\title{
Subsidios para o Estudo da Evolução Histórica da Execução das Sentenças no Direito Lusitano.
}

\author{
Luiz Carlos de Azevedo \\ Professor Assistente Doutor de Direito Processual \\ Civil na Faculdade de Direito da Universidade de \\ São Paulo.
}

1. Até a conquista da Lusitânia pelos romanos, raros são os testemunhos dispersos na palavra dos historiadores sobre os princípios que regiam os primitivos habitantes daquela região; ao lado dos clãs gentílicos dos celtas, os quais, mesclados aos líberos, iriam ser apelidados de celtíberos pelos cronistas helênicos e latinos, ali aportavam outras raças, com o jropósito de explorar ou manter o predomínio do comércio no Mediterrâneo. Foi o que sucedeu com fenícios, gregos e cartagineses, cada qual visando estabelecer seus núcleos e empórios, sem deixar, entretanto, arraigada à rudeza dos autóctones, maiores vestígios de suas culturas.

Subjugada a península por P. Cornélio Cipião e dividida a nova província romana em Citerior e Ulterior, - incluindo-se nesta a Lusitânia - primeiro Sertório e depois Júlio César procuram impor as instituições da República, entre elas, suas normas jurídicas e seu direito, que se estenderiam, mais tarde, a todos os súditos do Império.

O procedimento da execução das sentenças no Direito Romano, como é sabido, assim como todo o processo, conheceu, no curso de sua evolução, várias alterações: no primeiro estágio das ações da lei, era o próprio credor que se encarregava de cumprir a execução, exercendo-a sobre a pessoa ("manus iniectio") ou sobre os bens do devedor ("pignoris capio"). $\mathrm{Na}$ primeira hipótese, passado o prazo de trinta dias transcorrido entre a sentença ou confissão e a execução, não sendo quitada a dívida, podia o credor conduzir o devedor à força até o magistrado. Ao devedor não assistia afastar a mão do credor, sendo-lhe lícito, porém, socorrer-se de um "vindex", que acorria 
para cumprir o julgado e pagar o débito ou, então, para discutir a legitimidade da "manus iniectio", assumindo a causa em nome daquele. Ninguém comparecendo em seu auxílio, decretava a autoridade a "addictio", sendo o devedor levado a ferros até a casa do credor, ali permanecendo em custódia durante sessenta dias, ao cabo dos quais, não resgatado, seria vendido como escravo além Tibre, podendo o credor dispor livremente de seu corpo e até matá-lo, se assim o desejasse. No segundo caso, o credor, ainda por suas próprias mãos, apoderava-se dos bens pertencentes ao devedor, mantendo-os consigo até que o faltoso se dispuzesse a pagar a dívida.

O rigor destas disposições será amenizado nos períodos subseqüentes, quando se observam outros meios para a execução dos julgados e que se destinam mais contra o patrimônio do devedor que contra a sua pessoa: no formulário, a "actio iudicati", praticamente outra ação, promovida com vistas à execução da sentença condenatória e que se encerrava com o reconhecimento da dívida ou pela condenação em dobro, quando julgada improcedente a defesa argüida pelo devedor. Isto podia dar ensejo a outra "actio iudicati" e assim por diante até que ) débito fosse finalmente liquidado ou o pretor reconhecesse má fé no expediente empregado. A anuência do réu ao pedido formulado na "actio iudicati" levava a venda de seus bens em hasta pública ("venditio bonorum").

O sistema da "extraordinaria cognitio" trará características ainda mais humanas à satisfação dos julgados: a execução da sentença se faz por funcionário do Estado e vem proporcionada à dívida, isto é, não mais se apreende a totalidade dos bens do devedor, mas tão só aqueles que bastem à liquidação do débito ("distractio bonorum"). A venda pública dos bens acarretava, entretanto, a nota de infâmia sobre a pessoa do devedor, circunstância que se evitava quando este, voluntariamente, entregava seu patrimônio aos credores, ("bonorum cessio").

2. Além dos lindes do Império, situavam-se, entre outros povos, várias tribus germânicas, conhecidas pelo nome de godos e que se dividiam em dois grandes grupos: godos, acampados entre as estepes do Don e Dniester e visigodos, localizados entre este rio e o Danúbio (cf. J. M. Wallace-Hadrill, "El Oeste Bárbaro", trad. de Cesar Magrini, Ed. Univ. Bs. Aires, 1959, pg. 25).

Eram povos que, não obstante a aspereza de trato, produto da própria luta por uma sobrevivência árdua e espinhosa, pos- 
suíam uma certa "consciência de grupo", fundada em vínculos pessoais, onde a personalidade do chefe tribal traduzia a personificação de todo o povo; ali se destacavam certos costumes, tais como a "sippe" ou parentela, a simbologia do escudo e a continuidade da estirpe, a noção de companheiro e seguidores do chefe, - de onde surgiriam os condes - todos eles construindo uma sociedade de caráter tipicamente senhorial, em flagrante contraste com os aspectos inerentes a "urbs" romana. (veja-se, a respeito, Bernardino Bravo Lira, "Formación del Derecho Occidental", Ed. Jur. de Chile, Santiago, 1970, cap. VII).

Por outro iado, é destes povus de origem germânica que se importará, nos sêculos seguintes, a assembléia dos homens livres e dos homens bons da terra. - "mallum" - que tanta repercussão irá encontrar à época da formaçáo do reino luso.

Por volta do século IV, todavia, sofreriam os godos a investida dos hunos, provindos da Ásia, e não lhes podendo resistir, acabam por engrossar a leva de invasores que se precipita sobre o decadente Império romano.

Os visigodos atingem a península ibérica no correr do século VI, fixando ali poderoso reino, onde seus soberanos, fruindo a aura dos vencidos, assimilam as instituições romanas, inclusive no que diz respeito a legislação. $\mathbf{E}$ o que representa a "Lex Romana Visigothorum", ou "Breviário de Alarico", onde este rei manda reunir o Código Teodosiano, decisões do senado e dos pretores, opinião de jurisconsultos, com a finalidade de distribuir os ditames jurídicos ali incorporados a todos os seus súditos. Mas, agora, ao romano clássico se aduz o vulgar e ao texto original seguem-se-lhe paráfrases, com o intuito de adaptar o direito anterior ao povo que dele pretende se servir.

Esta preponderante influência romana, mais o Direito Canônico oriundo dos concílios, irão formar, com as primitivas instituições provenientes dos costumes germânicos, o amálgama de outra codificação, o "Liber Judiciorum", também conhecido como "Código Visigótico". Entre as várias disposições que tratavam dos "pennos" das "debdas", proibia a lei o emprego da penhora pela mão do credor: Defendemos á tod omne que non prende por sí. E si el omne que es libre prenda por sí mismo por fuerza á otri, pague el duplo del penno. E si el que prenda es siervo, peche el penno, é demas reciba C. azotes" ("Fuero Juzgo", Livro V, Título VI, n. I).

Tal proibição se destinava a coibir prática comum naqueles tempos; consoante acentua Enrico Tulio Liebman, "a penhora 
de autoridade privada era o ato pelo qual se conseguia coercitivamente do devedor a composição; correspondia a costume originário dos povos germânicos e somente à custa de grandes esforços se foi progressivamente restringindo pelas leis do rei. ("Embargos do Executado", trad. de J. Guimarães Menegale, S. Paulo, 1968, pg. 28). Por ser "estranha à mentalidade germânica" a idéia de que pudesse o indivíduo atribuir a parecer de terceiro a reparação da ofensa recebida, "procedia-se em larguíssima medida a prática da penhora privada e extrajudicial, sem qualquer intervenção do juiz" (id. ibid., pg. 33). Esta era a usança entre longobardos, quando vieram se estabelecer na Itália, mas assim também se procedia entre os visigodos, costume antigo e arraigado, que muito se alongaria no correr dos anos, apesar das leis dispondo o contrário.

Prescrevia ainda o "Código Visigótico" um número expressivo de disposições sobre a matéria, como, por exemplo, o penhor que devia ser dado pela dívida ou ainda a respeito daquele que trazia muitas dívidas e muitas culpas e, por não poder pagá-las, acabava reduzido à escravidão (Livro V, Título VI, ns. III e V).

3. Minado pelo fastígio de seu poderio ilusório, iria finar-se em breve tempo o Império Visigótico, mercê da rápida e contundente invasão islâmica. Os muçulmanos, contudo, por não pretenderem se imiscuir com os vencidos, que desprezavam, à parte teriam suas instituições e seu direito. Por outro lado, os remanescentes do destroçado reino, agadanhados às Astúrias, dali passariam a empreender, paulatinamente, a reconquista, tendo adotado, como herdeiros das tradições germânicas, os costumes provenientes daqueles povos. Não se desprezaram, assim, o direito e a lei dos visigodos, aos quais se adicionavam, porém, ordenações que os novos estados, recém-formados, cuidavam de elaborar.

Em tais condições, a par do direito posto, aplicado eruditamente, concorria com idêntico e senão maior vigor o direito costumeiro, do qual o concelho dos homens bons e as disposições foraleiras eram as suas mais características e autênticas expressões.

Antes de se circunscrever aos aspectos específicos relacionados com a execução das sentenças na prática geralmente observada, importa observar o que dispunham duas obras jurídicas da época, as quais, pela relevância e alcance, constituíram verdadeiras fontes concorrentes do Direito Lusitano, no momento em que o primitivo condado portocalense ganhava títulos de nação independente: faz-se referência às "Flores de las 
Leyes", de Jácome Ruiz e às "Sete Partidas", na parte em que tratam das execuções das sentenças. A primeira, no "titulo de cõmo se deue cõprir as sentenças das quaes non apelã nē podem apelar nem embargar", expõe quais as regras que devem ser adotadas após a sentença definitiva, devendo a coisa ou bem ser entregue ao "demandador" "sen perlongãça nenhua" (cf. ed. de Manuel Paulo Merêa, "A versão portuguesa das Flores de las Leyes, de Jácome Ruiz, Coimbra, Imp. da Univ., 1918, pg. 44).

Por sua vez, o Título XXVII da "Tercera Partida", estabelece como os juízos que "son valederos" devem ser cumpridos e quem pode cumprí-los; sem pretender se alongar sobre a matéria ali ventilada, ressalte-se: a Lei II, onde se afirmava que, reconhecida a dívida, mas teimando o vencido em não entregar a coisa, deviam os julgadores "ajuntar" homens armados e ir até ao local onde ela se encontrasse, cumprindo seu "juízo poderosamente, de maneira que a Justiça vença"; a Lei III informava em que bens incidiriam as execuções, enquanto a Lei $\mathrm{V}$ fixava o prazo de dez dias para o cumprimento da decisão; tratando-se de reaver coisa certa e não podendo o executado cumprir a sentença no prazo, podia este, caso não agisse com malícia, apresentar fiadores que por tudo se responsabilizariam até final liquidação do débito ou entrega da coisa; finalmente, a Lei VI descrevia a maneira como se vendiam os bens tomados a alguem, em razão de entrega ou de sentença. ("Las Siete Partidas", glosadas pelo lic. Gregorio Lopes, Salamanca, $1.555,2 .^{\circ}$ vol. pgs. 154 e sgs.)

Mas, muito embora assim se regulasse, o povo se atinha mais aos costumes que às prescrições legais; e é por isso que o processo se acomoda a quem dele se utiliza : entregue a pessoas rudes, simples, supersticiosas, carregadas de simbolismo, caracteriza-se pela oralidade e publicidade de seus atos, regendo-se pelos juízes da terra, eleitos pelos homens bons que compunham o concelho.

Para garantia da presença do réu, tomava-lhe o autor penhores. Ausente aquele, imitia-se o autor na posse de tais bens durante certo prazo, ao cabo do qual, poderia deles usufruir como lhe conviesse. Esta penhora ou arresto, feita "imediatamente pelo autor sem intervenção do oficial público e logo que intentava a causa", vem mencionada por Alexandre Herculano: "Esta usança, estranha aos nossos olhos, devia ser e era o arbítrio a que mais frequentemente se recorria para obter qualquer reparação judicial no meio da liberdade tumultuária dos concelhos, entre populações rudes e com a despro- 
porção que existia entre a força pública material e a violência e a soltura das paixões individuais". ("História de Portugal", Liv. Aillaud \& Bertrand-Fco. Alves, 1916, Liv. VIII, Parte III, pg. 134).

4. Característica do feudalismo é a disputa do poder entre o rei e o senhor feudal, inclusive no tocante ao exercício da atividade jurisdicional.

Em Portugal, ocorreria hipótese um tanto diversa, pois não há falar propriamente em feudalismo. Na verdade, o senhor das terras ali conquistadas aos mouros, não o fizera à sua conta, mas por delegação, primeiro do conde D. Henrique e, depois, dos reis da casa de Borgonha. Não existiu, assim, nos primeiros tempos da monarquia portuguesa, como ocorrera em outros países da Europa, o estabelecimento da soberania feudal par a par com a soberania real. O que sucedia, realmente, era a existência fática de um direito costumeiro, que se definia nos concelhos e forais, muitos destes anteriores à fundação do reino e que portavam toda a carga de séculos de tradições germânicas; mas, se assim era, existia, de outro lado, a Curia Régia, instituto de inspiração haurida do Direito Comum, e que se baseava nas doutas disposições das primeiras universidades.

O poder real vai se fixando gradativamente, afastando a resistência dos senhores da nobreza e clero, que haverão de ceder às leis gerais, dispostas por Afonso II, Afonso III e pelo filho deste, D. Dinis, sempre com o propósito de fortalecer e concentrar a autoridade em suas mãos. Com o primeiro destes monarcas, são realizadas as Côrtes de Coimbra, que irão representar "a primeira fórmula de organização interna para assegurar e fortalecer a soberania da coroa. Delas saíram as leis gerais do reino, que traduzem o pensamento de que o rei é, não só o detentor tradicional do poder político e da suprema jurisdição, mas também o único agente da ponderação social" (in Dic. da Hist. de Portugal, Liv. Figueirinhas, Porto, 1971, pg. 608).

E por esta razão que Afonso II estabelece que a execução não se fará por qualquer, mas por seu porteiro, o qual, seja com fuste, seja com letras, não poderá ir além do que lhe foi determinado. (Livro das Leis e Posturas, Univ. de Lisboa, 1971; pg. 12). Tal determinação passaria às Ordenações Afonsinas, Liv. III, Tit. 92, 1. Ainda de D. Afonso e do mesmo ano, - 1.211 - é a lei que dispõe sobre o cumprimento da penhora, restrita tão somente àqueles que possam provar quem é seu devedor ou fiador. (Liv. das Leis e Posturas, pg. 15). 
A proibição da penhora pelas próprias mãos é referendada por lei de Afonso III, enquanto que, mais tarde, D. Dinis estabelece como se devia agir quanto aos bens do vencido, no caso de não pagamento da dívida. (1.320) (Liv. das Leis e Posturas, pg. 126).

Em 1.342, Afonso IV regula a forma das execuções que sacadores e porteiros deviam fazer por motivo de dívidas, (Liv. das Leis e Posturas, pg. 407), indo a disciplina até a compilação Afonsina, Liv. III, Tit. 89, 1.

Em suma, como já se ressaltou, a liberdade do credor vai sendo cerceada, cingindo-se a sua ação ao prévio conhecimento e autorização do juiz; às antigas formas de execução, provindas do Direito Romano, e aos costumes germânicos, agora estancados pelos diplomas legais, sobrepõem-se novos tipos de procedimento: é o caso da "executio per officium iudicis", "segundo a idéia original de Martinho Difano, acolhida por Giovani Fasolo e Durante", (ALCIDES DE MENDONÇA Lima, "Com. ao Cód. de Proc. Civil", Forense, 1974, vol. VI, t. 1, pg. 47) ou seja, "a execução forçada" ou "execução da sentença", "procedimento ou prosseguimento ao em que se proferira a sentença condenatória" (MOACYR AMARAL SANTOS, "Direito Processual Civil, vol. 3. ${ }^{\circ}$, pg. 223).

5. Havia necessidade de se compilar toda a obra legislativa do reino, até então dispersa e desordenada, pois resultara do mandamento de vários governantes, no que haviam sido subsidiado por não pequeno número de Cortes. E o que revela o chamado "Livro das Leis e Posturas", onde se apresenta aspirada mas ainda incipiente pretensão de se coligir tudo quanto se dispusera a respeito de leis, o que se faz, contudo, ainda sem método e seqüência.

A idéia se concretiza com as Ordenações Afonsinas, promulgadas em 1446: constam de cinco livros, tratando, o terceiro, da parte processual. 0 processo de conhecimento divide-se em ordinário e sumário: aquele, solene, escrito, formal; este, mais simples e rápido, inspirando-se na "Clementina saepe" Quanto ao processo de execução, já se encontra, a essa altura, inteiramente estruturado: a penhora, cumpre-a o porteiro. (Liv. III, Tit. 92). Admitem-se embargQs do executado à sentença e à arrematação, traduzindo-se aí, a origem do nosso sistema de execução das sentenças. Os embargos, criação tipicamente lusitana, apareciam sob várias formas no regime Afonsino: eram "um meio para impedir a contestação da lide (Tit. 55, pr. e Tit. 57,4) e, depois, para impedir a prolação da sentença definitiva de mérito. (Tit. 
55, pr. e 2 e Tit. 66,5). Proferida a sentença, era um recurso para obstar seu trânsito em julgado. (Tit. 55, 3, 4 e 5 e Tit. 56, pr. e 1 ). E, finalmente, um meio para impedir a execução do julgado e a arrematação dos bens" (Tit. 56, 1; Tit. 79, 1 e 79, 1, 2 e 6 ; Tit. 92, 2. Tit. 105, pr.). (Cf. MOACYR LoBo DA Costa, "Origem dos embargos no Direito Lusitano", Borsoi, Rio, 1973, pg. 16). E quanto a tais aspectos, porque o juiz pudesse duvidar quais fossem embargos e quais fossem razões, que embargassem a execução e que se podiam por e alegar contra ela, deveria de tudo se informar nos Títulos que tratavam das exceções peremptórias e de quando se poderá apelar do executor da sentença. (Liv. III, Tit 89,6).

O Título 92 dispunha sobre a "execução que se faz por porteiro e do que lhe tolhe o penhor", reproduzindo a velha disposição de Afonso II; e como se diz hoje que o oficial é o próprio braço do juiz que se estende até o devedor para que venha a ser satisfeita a pretensão do credor, representava o porteiro, ao executar a sentença, a autoridade real: aquele que "lho forçosamente contradizesse, fosse preso e apenado"

A execução fazia-se antes nos bens móveis que nos de raiz e, só à mingua dos primeiros, passaria a estes. (Tit. 93). Por outro lado, conforme antiga lei de Afonso IV, os bens oferecidos pelo executado ou que estivessem fora de sua casa, precederiam aos móveis e alfaias desta. (Tit. 98). Vinha desde D. Pedro disposição pela qual não se deviam executar bens além daqueles necessários à satisfação do débito. (Tít. 103). A precedência da primeira penhora, repetindo leis anteriores de D. Dinis e D. João I, aparece no Título 97, por onde se conclui que "se dois credores houverem sentenças contra um devedor, quer no mesmo, quer em diversos juízos, aquele que primeiramente fizer a execução da sua sentença precederá o outro, ainda que este seja primeiro no tempo" Não sendo interrompida, prescrevia a execução da sentença em quarenta anos, (Tít. 103) prazo que se reduzirá, mais tarde, a trinta anos. Do reinado de D. Fernando, (1404) é a lei que trata da maneira como há de se fazer as arrematações, fixando-se ali os prazos aos eventuais embargos. (Tít. 106).

Às Afonsinas, seguir-se-iam as Ordenações Manoelinas, em vigência na segunda década do século XVI. Acentua-se a influência do Direito Romano-Canônico e o processo passa a se revestir de caráter extremamente formalista. Repetem elas, na parte relativa às execuções, muitos dos títulos contidos na lei anterior. A penhora será feita em tantos bens 
quantos parecer ao oficial, bastarão para o cumprimento da ordem, (Liv. III, Tít. 70, 4) dando-se preferência aos móveis que aos imóveis, (Tít. 70,5) e ficando o funcionário responsável pelos excessos que porventura cometer. (Tít. 70, 5, "in fine"). Da penhora são excluídos certos bens, como cavalos c armas dos que estivessem a serviço do rei, ou sementes e bois de arado dos lavradores, que de ambos careciam ao trabalho nas herdades. (Tít. 71, 11, acompanhando o Tít. 98 das Afonsinas e antiga disposição das Cortes d'Elvas, ao tempo de D. Pedro I). Corriam os pregões dos bens móveis dez dias contínuos após a penhora e, dos bens de raiz, trinta dias da mesma data, descontados os domingos e dias santos, (Tít. $71,12)$ ao cabo dos quais eram eles arrematados e vendidos para quem melhor preço ofertasse.

Eram conhecidos três tipos de embargos na fase de execução da sentença: remetidos, (Tít. 71) à arrematação e modificativos, (e não só ofensivos, como prevê o Tít. 60) vindo estes no referido Título 71, 18. Por outro lad.o, surge, pela primeira vez, a figura dos embargos de terceiro. (Tít. 71,32 )

Com outras palavras, transcreve o Título 72 o que já haviam dito as Afonsinas a respeito dos "que resistiam à Justiça": assim procedendo, incorreriam nas sanções previstas no Livro v, específico do Direito Criminal.

Afirma-se, com maior amplitude, a matéria concernente a precedência da primeira penhora, (Tít. 74) a qual passaria à compilação subseqüente. (Ord. Filipinas, Liv. III, Tít. 91) .

Ainda que rebuscadas e formalistas, as Ordenações Manoelinas iriam contemplar, contudo, um novo tipo de procedimento, ao qual dariam o nome de "ação decendiária": (Liv. III, Tít. 16) era a ação do credor para haver do devedor quantia ou coisa, a cuja prestação este último se obrigara, conforme fazia prova escritura pública ou alvará feito e assinado. Assinava-se ao réu, em tais condições, dez dias para que viesse pagar a obrigação contida no título ou oferecer embargos, nos quais: a) elidia o pedido, provando a inegibilidade da dívida, v.g., pela quitação; b) alegava a inegibilidade da obrigação; neste último caso, desde que aceitas pelo juiz as razões do alegado, assinava-se termo para que o réu viesse exibir os documentos com os quais pretendia contrapor aqueles fornecidos pelo autor ou, ainda, para que se ouvissem, desde logo, as testemunhas indicadas. Recebidos os embargos, podia o autor, querendo, promover a execução, que se fazia sem qualquer outro recurso; mas, para haver 
mão do pretendido, depositava fiança; não o fazendo, ficava a quantia ou coisa depositada "em mão de pessoa fiel e abonada". Se o réu viesse a ser absolvido do conteúdo da obrigação, era o autor condenado a pagar tudo quanto desembolsara aquele, custas, despesas processuais e mais ainda outro tanto de pena. Do mesmo modo o réu, não logrando provar aquilo que alegara, além da condenação principal, era compelido a pagar outro tanto de pena. Desta condenação em dobro, parte se destinava ao vencedor na causa e parte à Piedade. Em resumo, na ação decendiária, o réu pagava ou melhor, depositava - a importância correspondente a dívida líquida e certa, mas o feito prosseguia; reconhecida a temeridade com que se houvera qualquer das partes, arcaria ela com a condenação em dobro.

Não se tratava, todavia, da "actio iudicati", conforme pretendem alguns autores, pois é certo que a última não na conheceram os lusos; a respeito, aponta AICIDES DE MENDONÇA Lima, valendo-se de lição de LIEBMAN, os traços diferenciadores de ambas, em especial quanto aos seus respectivos objetivos. Se é certo que com a introdução da ação decendiária, "operou-se a metamorfose do processo executivo em processo de cognição sumária, no sentido de que, nessa última, a escritura não autorizava a imediata execução e, sim, tão-somente, a obtenção célere da sentença, para depois ensejar a execução, mas pela via ordinária", não há como confundí-las, apesar de seus aspectos semelhantes. (cf. AICIDES DE MENDONÇA LIMA, op. cit., pg. 50).

6. Nas Leis Extravagantes, coligidas pelo licenciado Duarte Nunes de Leão já ao tempo de D. Sebastião, em seguimento ao propósito do rei anterior, D. João III, quanto a simplificar e acelerar o andamento dos processos, procurou-se dar maior clareza e definição aos institutos constantes da nova ordem do juízo. (Parte III, Tít. I, LVII). Assim, na matéria relativa a execução das sentenças, impedem-se recursos protelatórios e procrastinadores, determinando-se que no caso de ser apresentada exceção de suspeição, "se não detenha a execução e nem os pregões deixem de correr", devendo outro juiz assumir o comando do feito. (Parte III, Tít. I, LVII, 40). No mais, guardavam as execuções das sentenças as linhas mestras dos trâmites dispostos nas leis anteriores, incluindo-se nestas, a Lei de 13 de setembro de 1557.

De relevar, finalmente, a Lei $v$, do Título viII, dessa mesma Parte III do chamado "Código Sebastiânico": acompanhando o caráter instrumental que devia ditar toda a 
ordem do juízo, determinava a lei não se anulassem execuções ou arrematações por "falta de pequena solenidade" Disposição de conteúdo significativo, esclarecendo que as formalidades, tanto àquele tempo, como hoje, nada mais são do que meios para atingir a finalidade de determinado ato e a sua inobservância não induz, necessariamente, a nulidade, mormente quando se atingiu o objetivo pretendido.

7 Não foram muitas as novidades e modificações introduzidas com as Ordenações Filipinas. Longe de pretender impor a legislação do país vizinho, tiveram elas, como causa imediata a necessidade de revogar certas disposições aceitas pelo rei e cardeal D. Henrique, quando do Concílio de Trento. Por isto, seguem o mesmo diapasão das anteriores, muito embora persista a preocupação de se escoimar o que restava de complexo e duvidoso.

o quadro abaixo permite fornecer uma visão dessa ascendência cronológica:

Origem Título nas Afonsinas

Lei de Afonso

IV, 1.342 .

L.L.P., pg. 407

Direito

Romano

Lei de Afonso

II, 1.211

L.L.P., pg. 12

Lei de D. Dinis 1.320

L.L.P., pg. 126

\subsection{3}

Lei de D. Dinis 1.283

L.L.P., pg. 182

Lei de Afonso IV rei. penhor nos de raiz certas pessoas $\begin{array}{llllll}\text { Das Execuções que se fazem } & 89 & 71 & 86\end{array}$ geralmente pelas sentenças

Se citaram a parte condenada ao tempo da execução que se faz pelo porteiro, em razão de seu ofício, sem outra carta do

Da execução que se faz por porteiro e do que lhe tolhe o

Como primeiro se há de fazer execução nos bens móveis que

Que não dê o rei porteiros especiais para fazer execução onde houver mordomos senão a

Da maneira que hão de ter os sacadores que o rei dá a alguns por graça especial nas execuções
Af. Man. Fil.

$91 \quad 71 \quad 86$

$\begin{array}{lll}92 & 72 & 89\end{array}$

$\begin{array}{lll}93 & 71 \quad 86\end{array}$

$\begin{array}{lll}94 & 73 & 90\end{array}$ 
Lei de D. Dinis 1.301

L.L.P. pg. 195

Quando o rei der cartas a alguns

$\begin{array}{lll}96 & 73 & 90\end{array}$ prelados, que ajam porteiros ou sacadores, ponha-se fé em elas, que os mordomos não percam o seu direito

Lei de D. Dinis e D. João

L.L.P. pg. 180

Lei de D. Pedro

Do credor que primeiramente houver sentença e fizer execução, que preceda outras todas, ainda que sejam primeiras no tempo

$\begin{array}{lll}97 & 74 & 91\end{array}$

Que não façam penhora ou execução nos cavalos e armas dos vassalos

Lei de Afonso Que não entrem porteiros nas IV casas dos condenados a fazer

$\begin{array}{lll}99 & 71 & 86\end{array}$ execução se acharem penhoras fora delas

Lei de Afonso IV

De como se há de fazer exe- $\begin{array}{lll}100 & 71 & 86\end{array}$ cução nas casas dos fidalgos, cavaleiros ou donas

Lei de D. Pedro Que não façam execução em $104 \quad 71 \quad 86$ mais bens do condenado que possam satisfazer a dívida

Dispôs o legislador filipino, no Livro III, Título 66, 9, a confissão da parte, determinando o juiz, nessa hipótese, se procedesse a execução para que pagasse o réu a dívida, ou entregasse a coisa confessada, por que fora demandado; não se tratava, todavia, de sentença condenatória, mas de mandado de "solvendo", conforme já haviam feito referência, aliás, as Leis Extravagantes. (P. I, Tít. 17, Lei I, 6)

Quanto a ação decendiária, prevista no Livro III, Título 25, deixa de haver salutar disposição, no sentido de se exigir a restituição da condenação em dobro, para autor e réu, da maneira como bem haviam fixado as Ordenações Manoelinas. Por outro lado, não se repetiu todo o texto contido no antigo diploma, onde se distinguiam as duas matérias, execução de sentença e assinação de dez dias:

ORDENAÇÕES

MANOELINAS

LIV. III. Título 16

§ 5: E queremos que isto, que dito é das dívidas que se de-
ORDENAÇÕES FILIPINAS

Livro III, Título 25

§ 8: E queremos que isto que dito é das dívidas que se de- 
mandam por escrituras públicas, haja isso mesmo lugar em qualquer dívida que se dever e demandar por vigor dalguma sentença, que passar em coisa julgada, quando se demandar por via de ação que nasça dessa sentença.

$\S 6 .^{\circ}$ : E quando a dívida contida na sentença se demandar por via de execução, requerendo que se execute a sentença nos bens do condenado, se cumprirá o que é dito no Título "Das Execuções que se fazem geralmente pelas sentenças" e o que por outras Nossa Ordenações acerca das execuções das sentenças é determinado.

$\S 7 .^{\circ}$ : E esta Ordenação se entenderá somente nas próprias pessoas que fizerem as tais escrituras e não em nenhumas outras pessoas. mandam por escrituras públicas, haja lugar em qualquer dívida que se dever e demandar em virtude de alguma sentença que passar em coisa julgada, quando se demandar em virtude de ação que nasça dessa sentença.

\section{SEM CORRESPONDENTE}

$\S 100^{\circ}$ : E esta Ordenação se entenderá somente nas próprias pessoas que fizerem as tais escrituras, e não em outras nenhumas pessoas, posto que sejam herdeiros.

Tal omissão é que daria ensejo às dúvidas e contradições dos que, mais tarde, vieram interpretar o texto legal; comentando a famosa Lei de agosto de 1769, conhecida como "Lei da Boa Razão", e ao tratar do sofisma "ex accidenti", que "he quando a huma cousa se attribue como necessário aquillo que "per accidens" lhe pode competir", José Homem CORREIA TELLES assinala, a esse propósito, o seguinte exemplo: "A Ord. Liv. 3, Tit. $25 \S 8$ diz que se da sentença nascer acção pela qual hum possa demandar a outro certa quantia, aquelle a possa pedir por assignação de dez dias. Deduzir desta Lei, que toda a sentença pode ser executada por assignação de dez dias, he sophisma, no qual tropeçarão Moraes - de Execut. Liv. 2, cap. 6, n. 5 e Silva no Comment. áquella Ord: porque por huma parte as execuções tem a forma de processo ordenada na Ord. Liv. 3, Tit 86 ; e pela outra só "ex accidenti" pode succeder, que de huma sentença nasça acção diversa daquella, que finalisou pela sentença mesma" ("Comentário 
Crítico à Lei da Boa Razão, em data de 18.8.1769", Lisboa, 1836, Tip. de Antonio José da Rocha, §7. ${ }^{\circ}$, n. 32, pg. 20).

Melhor esclarece ainda, o "Manual Prático" de um contemporâneo da mencionada lei, ALEXANDRE CAETANO GOMES: descreve ali o autor, com certa originalidade e graça, como os tratadistas, a seguir, sem maior apuro ou exame, um de seus pares, Caldas, como o primeiro se enganaram, como às vezes sucede com as aves, "pois quando huma vôa, as outras a seguem"

$\mathrm{E}$ argumentando, acrescenta que se o legislador das Ordenações quis dar a escritura o procedimento sumário, que de direito comum era ordinário, não seria verossímil que a sua intenção fosse conceder à sentença o mesmo privilégio, "quando de sua natureza o tem, não só sumário, como executivo"

Realmente, se esse fosse o seu escopo, teria dito "quando se demandar por via de ação que nasce dessa sentença; ao contrário, o uso do subjuntivo nasça, condicional e fortuito, vem aclarar que não se trata da ação que nasce da sentença para aquilo que foi julgado; mas sim, de um caso especial, ou seja, "quando suceder que na sentença nasça ação, para se pedir alguma cousa, de que nessa sentença não haja condenação direta; quando se demandar por via de ação, que nasça dessa sentença” (Manual Prático Judicial, Civil e Criminal”, Lisboa, Tip. de Antonio José da Rocha, 1854, §§ 6, 12, 13, 14, 15 e 16, pgs. 183 e sgs.).

Em tal caso, e só neste, é que, preenchidos os demais requisitos dispostos na lei, seguirá o pedido o rito sumário, isto porque "as demandas, que são fundadas em escrituras públicas, devem brevemente ser acabadas" (Ordenações Filipinas, Liv. III, Tít. 25, pr..). Revela-se aqui, o intuito do legislador de então, cioso por apressar a morosidade exasperante dos processos e fazendo empenho por referendar, senão com igual clareza, pelo menos com idêntico objetivo, tudo quanto já dissera a ordenação anterior.

De tal sorte, conclui-se que o Direito Português não contemplou, em nenhuma das duas codificações, a chamada "actio judicati", como pretenderam alguns, e é o mesmo advogado e presbítero flaviense quem arremata: "Onde as palavras: Quando se demanda por via de execução, mostrão que a Lei falla de hum só modo de executar; e sendo contrapostas ao $\S 5 .^{\circ}$, nas palavras por via de acção que nasça dessa sentença, 
ainda mais claramente mostrão que não tratou do modo de executar pela acção "in factum", "seu judicati", mas só "officio judicis", deixando só para o caso de nascer alguma acção pela sentença o pedir-se por via summaria, assim como se propõe a acção de escritura pública". (op. cit. $\S 28$, pg. 186).

Mais tarde, em suas "Dissertações Jurídicas sobre a inteligencia de algumas ordenações do Reino", que vieram complementar o "Manual Prático", censuraria ALEXANDRE CAETANO GOMES, "sem sair dos limites da modéstia", os erros de alguns praxistas reinícolas, voltando ao mesmo assunto para repisar a inadvertencia de Moraes, Valasco e Caldas; e, ao se referir a "actio judicati", acrescentou que o $\S 8 .^{\circ}$ do Tit. XXV jamais poderia ter falado desse modo de execução, "que os mesmos Doutores estrangeiros, que o referem de Direito Comum, confessam que é prejudicial" ("Dissertação VI, ad. Ord. lib. 3, Tit. 25, Lisboa, Of. de Domingos Gonçalves, 1756, $\S 77$, pg. 256).

Grande era o cuidado de se encontrar a verdadeira interpretação dos textos legais, perdida no emaranhado das reiteradas citações dos mestres do Direito, as quais serviam amiúde à malícia e perspicácia de certos advogados, interessados em atravancar a marcha dos feitos; e, por isso mesmo, alguns anos depois a Lei da Boa Razão, imbuída de espírito essencialmente prático e utilitarista, daria cobro a tais incertezas e hesitações e, assim também, às "extravagantes subtilezas" daqueles que, a esse tempo, aconselhavam e promoviam as demandas.

8. Conforme assinala WALDEMAR FERREIRA, "correram séculos, reis e rainhas se sucederam na posse e administração da Corôa, e as Ordenações Filipinas subsistiram, adaptando-se às necessidades dos povos e dos tempos. Têm elas na anciania respeitada e respeitável a aureola da sua grandeza. Vigoraram durante duzentos e sessenta e quatro anos, mais de dois séculos e meio, em Portugal" (História do Direito Brasileiro, Freitas Bastos, Rio, São Paulo, 1952, Tomo II, pg. 330).

No Brasil, a vigência iria se alongar por mais cinqüenta e oito anos, valendo como lei até princípios do século $\mathrm{XX}$. Verdade é que, a essa ocasião, de muito se havia derrogado o Livro $\mathrm{V}$ e para mais de sessenta anos o processo civil e comercial se regulava por outras disposições.

Não obstante, toda essa longevidade, cuja origem se perde na gama dos tempos, mas a qual nos arraigamos, como se atavicamente a ela pertencessemos, soube aportar o espírito 
rude mas sincero dos costumes foraleiros e, com eles, o municipalismo, e permitiu formar uma visão legislativa - como tiveram os antigos reis de Portugal, capazes de construir o primeiro código europeu, nos idos do século XV - fundamentando uma tradição liberal e civilista, que indubitavelmente, nos orgulha e nos conforta. 